\title{
Green Marketing to Young Adult Students: Is It Effective or Not? (A Research on the College Students of India in the Age Group of 17-25)
}

\author{
${ }^{1}$ Nikhil Agarwal, ${ }^{2}$ Akhil Agarwal, \\ ${ }^{1}$ Student, Department of Commerce, Shri Ram College of Commerce \\ ${ }^{2}$ Student, Department of Electronics \& Communication, Meerut Institute of Technology
}

\begin{abstract}
Green Marketing involves building lucrative customer relationship with concern and care for the environment. The aim is to reduce the negative effect of the organisation's activities on the environment and make the entire process from production till supply of product eco-friendly. Almost all the organizations across the world are engaging in this process but are unaware of the results which this campaigns/process are generating.

This research paper aims to study the effectiveness of green marketing by the firms on a specific consumer group i.e. students in the age group of 17-25.Many companies like Classmate(ITC), Coke derive a substantial market share from the student consumer groups. For companies to be successful in green marketing campaigns, they need to ensure that consumers are actually aware of the idea of this concept. They should have a concern about the nature \& environment. Then only, they will be affected such campaigns otherwise the efforts will be wasted.

Keeping this thing in mind, the research invokes mind-boggling facts which can significantly affect the behavior of various consumer good companies.
\end{abstract}

Keywords: Green Marketing, Green products, Young adult students, effectiveness of the Campaign, awareness.

\section{Introduction:}

Green marketing involves balancing environmental issues with the consumer needs. According to Jacquelyn Ottman, an organization should integrate environmental considerations into all the aspects of marketing: new product development, communications and in all steps from the development of product to the commercial to the commercialization of the new product i.e. designing the product, manufacturing the product, transporting the product, promotion and advertising. Therefore, the term green marketing can be defined as follows:

\section{GREEN + MARKETING $=$ GREEN MARKETING}

"Marketing" means building profitable customer relationships. The term "Green" connotes the environmental concern. Therefore, the term green marketing means building lucrative customer relationship with a parallel concern and care for the environment. Therefore, all the activities which are done as a part of the marketing process combined with the element of sustenance and care for the nature, environment constitutes green marketing.

\section{How Does The Organizations Get To Know About The Effectiveness Of Their Green Marketing Campaign And Its Contribution In Their Brand Image Building?}

The organization needs to continuously evaluate its green marketing campaign in order to

- $\quad$ By ensuring that the consumers are aware of the campaign by the organization.

- By knowing that consumers are aware of and concerned about the issues that marketer's profess to address.

- Consumers feel that by using the marketer's product they will make a difference to themselves and the society.

- The product receiver/user should believe in marketer's campaign.

- $\quad$ The person should be concerned about the environment.

- $\quad$ The product must satisfy the claims made. 
- If the marketer is burdening the consumer by an extra premium then the consumer must comprehend that to be worth and justifiable.

\section{Benefits Of Green Marketing To The Organization:}

A business firm benefits from the environmental marketing in numerous ways, if it turns out to be effective. It improves the public image of the organization and builds brand value. It increases the customer base of the organization and enable it to flourish(earn gargantuan profit margin) in the long run. The organization also avoids unnecessary intervention of the government authorities.

\section{Challenges Before The Green Marketers :}

There are a number of myths that subsist in the minds of the consumers. They pose a major challenge for the marketers. According to Jacquelyn ottman, following are some of the myths which are in existence in present scenario:

- Green products don't work well.

- Green products are more expensive.

- Only speciality stores sell green products.

- Green products aren't really green.

- Natural products are more healthful.

- $100 \%$ recycled products are better than $20 \%$ recycled products.

Costs To Business For Green Marketing:

- High Promotion and advertising cost.

- High distribution cost.

\section{Young Adult Students As An Important Consumer Base:}

According to the census of 2011, the total population of India is $\mathbf{1 , 2 1 0 , 1 9 3 , 4 2 2}$. The total number of students enrolled in higher education are 1,69,75,000 which is about $1.402 \%$ of the total population. Therefore, it constitutes a major potential customer base for the business organizations, in particular, like notebook manufacturing etc. Classmate, a leading notebook manufacturer, has its $50 \%$ of market share coming from these students only.

\section{Literature Review:}

According to Mr.Hemantha Y's research on the consumers in the Bangalore city, the consumers are highly aware about the concept of green marketing. Their attitude towards green branding is high. In general, the people perceive green marketing as a positive concept.

\section{Research Methodolgy:}

Researcher has used the structured questionnaire method to conduct the survey and collect the responses from the students. Responses from 80 students from different states of the country India were collected to measure the effectiveness of green marketing among the young adult students consumers group . The responses were restricted to 80 due to limitation of time factor. The questionnaire was put up online on social media platform in the groups of Delhi University students Delhi university has the student base from different states of India. Random sampling was adopted by the researcher and a sample comprising of students from different genders,states, culture were selected. This primary data was analyzed and the conclusion was made on the basis of concentration of data towards about a particular response using the percentage method

The questionnaire method was chosen for its versatility speed and cost benefits.

The study has been done keeping in mind the following objectives:

- Are the young adult students of the country aware of the green marketing because if they are'nt aware then the green marketing efforts of the firms whose major consumer group is these students will go futile.

- Are the students environmentally concerned and does the green marketing efforts affect the purchase behavior of consumers?

- Are the environmental marketing efforts of the firms converting into sales?

- If not, then what steps should be taken to do so? 


\section{Data Analysis And Interpretation}

Table 1. Demographic Profile of Respondents

\begin{tabular}{|l|l|l|}
\hline Gender & Number of Respondents & Percentage \\
\hline Male & 54 & 67.5 \\
\hline Female & 26 & 32.5 \\
\hline
\end{tabular}

Table 2. Geographic Profile of Respondents

\begin{tabular}{|l|l|}
\hline State & Number of respondents \\
\hline Delhi & 17 \\
\hline Jharkhand & 2 \\
\hline Uttar Pradesh & 9 \\
\hline Karnataka & 1 \\
\hline Tamil Nadu & 19 \\
\hline Rajasthan & 8 \\
\hline Bihar & 4 \\
\hline Punjab & 3 \\
\hline Sikkim & 1 \\
\hline Haryana & 8 \\
\hline West Bengal & 5 \\
\hline Madhya Pradesh & 1 \\
\hline Uttarakhand & 1 \\
\hline Telangana & 1 \\
\hline Total & $\mathbf{8 0}$ \\
\hline
\end{tabular}

Table 1 shows that the $67.5 \%$ of the responses were from males and the remaining from females.

Table 2 depicts that the data collected consisted of responses from almost 14 states. Although the number of responses from each state were very small but a general trend among the students in the same age group belonging to different cultures and states can be observed.

\begin{tabular}{|l|l|l|}
\hline $\begin{array}{l}\text { 1. I which order do you consider the } \\
\text { following factors while making purchase of a } \\
\text { product: } \\
\text { Price, Brand, Eco-friendliness, Easy } \\
\begin{array}{l}\text { Availability of the product ( Place Utility)? } \\
\text { Priority to Eco-friendliness/Green } \\
\text { Products }\end{array}\end{array}$ & Percentage \\
\hline First priority & 3 & \\
\hline Second Priority & 15 & \\
\hline Third Priority & 17 & 3.75 \\
\hline Fourth Priority & 45 & 18.75 \\
\hline Total & $\mathbf{8 0}$ & 21.25 \\
\hline
\end{tabular}

Around $75 \%$ of the young adult students do not consider the environment friendliness of the products. Around $45 \%$ of the students consider brand as the first factor which decides their purchase behavior. Around $37.5 \%$ of the students consider, Price as the top deciding factor of their decision to purchase a product. A meagre portion of students consider environmental factor while making such decision.

2.Do you use green products in your daily life.

\begin{tabular}{|l|l|l|}
\hline Response & Number of respondents & Percentage \\
\hline Yes & 31 & 38.75 \\
\hline No & 7 & 8.75 \\
\hline Don't know & 42 & 52.5 \\
\hline Total & $\mathbf{8 0}$ & $\mathbf{1 0 0}$ \\
\hline
\end{tabular}




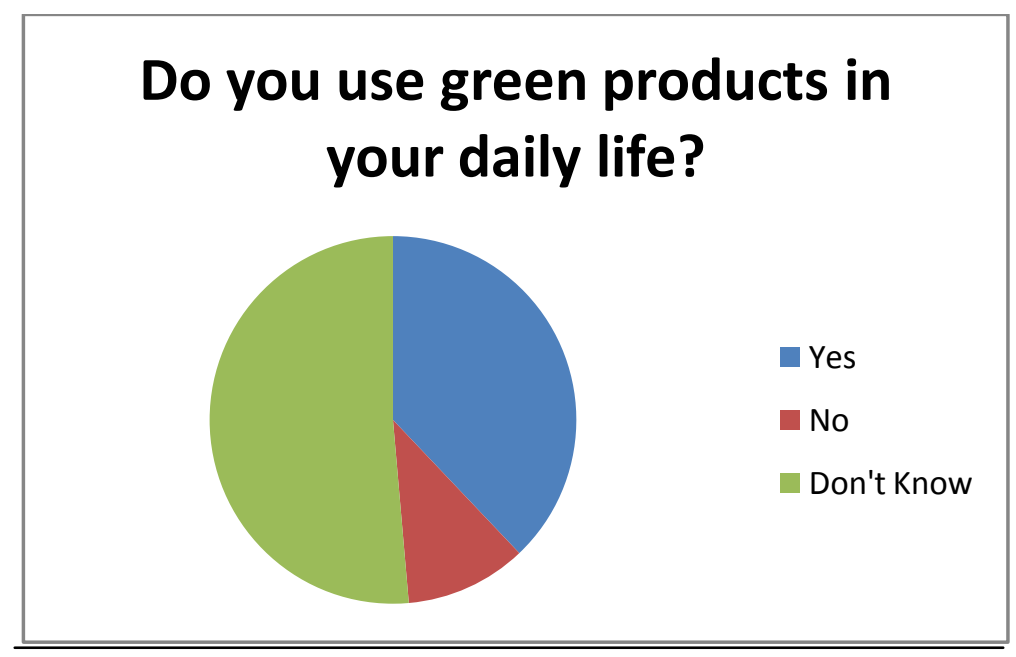

More than half of the population surveyed is unaware of the fact that whether they use green products in their daily life or not.

3. If you are given a choice between a environment friendly product and a non environment friendly product, which one will you buy? ( Assuming that the eco-friendly product is expensive as compared to the non-eco friendly product)

\begin{tabular}{|l|l|l|}
\hline Response & Number of Respondents & Percentage \\
\hline Environment Friendly & 50 & 62.5 \\
\hline Non-Environment Friendly & 30 & 37.5 \\
\hline Total & $\mathbf{8 0}$ & $\mathbf{1 0 0}$ \\
\hline
\end{tabular}

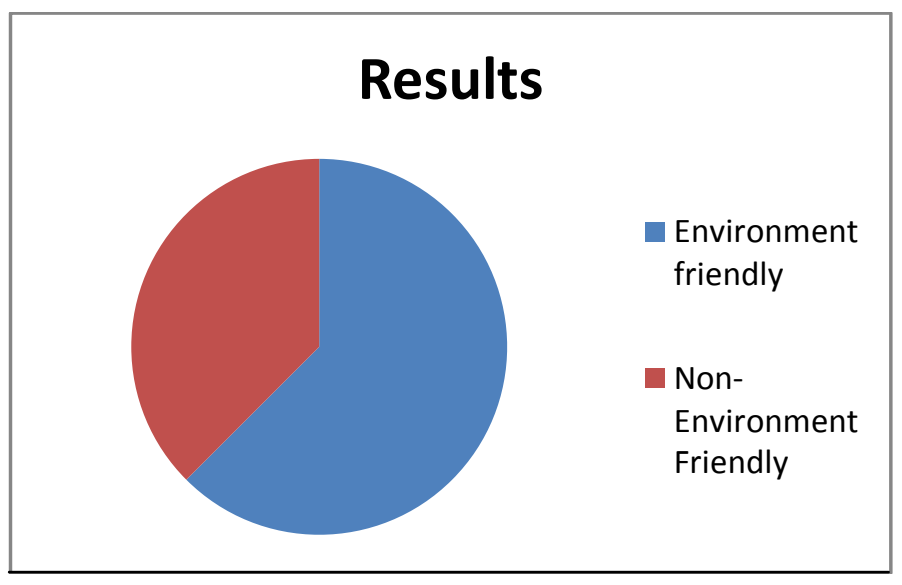

This question results that if given an opportunity to buy the goods, around $62.5 \%$ of the people will buy Eco-Friendly goods even if they are expensive.

4. Are you aware of the concept of green marketing?

\begin{tabular}{|l|l|l|}
\hline Response & Number of Respondents & Percentage \\
\hline Not Fully Aware & 61 & 76.25 \\
\hline Fully aware & 10 & 12.50 \\
\hline Not aware & 9 & 11.25 \\
\hline Total & $\mathbf{8 0}$ & $\mathbf{1 0 0}$ \\
\hline
\end{tabular}




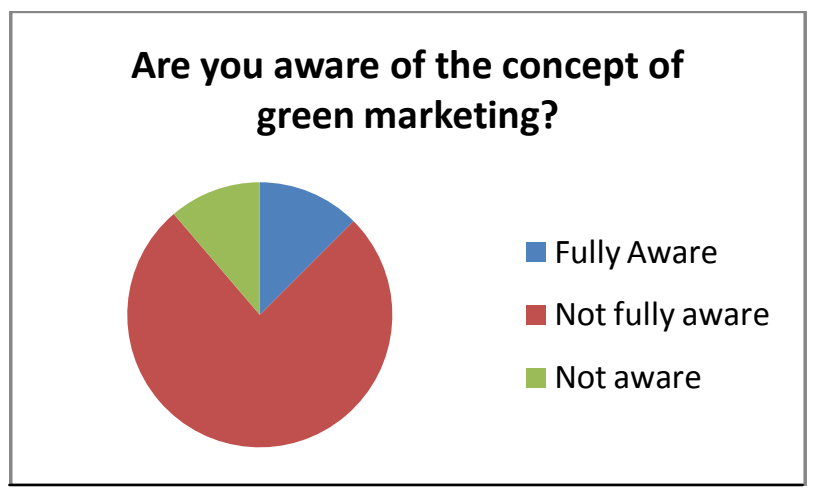

Around $3 / 4^{\text {th }}$ of the population surveyed in not fully aware of the concept of green marketing. They just have an idea. As we know, Incomplete information leads to a lot of questions in mind which ultimately prevents the consumer from buying green products.

5. Are you aware of the companies involving themselves in green marketing?

\begin{tabular}{|l|l|l|}
\hline Response & Number of Respondents & Percentage \\
\hline Not Fully Aware & 45 & 56.25 \\
\hline Fully aware & 6 & 7.50 \\
\hline Not aware & 29 & 36.25 \\
\hline Total & $\mathbf{8 0}$ & $\mathbf{1 0 0}$ \\
\hline
\end{tabular}

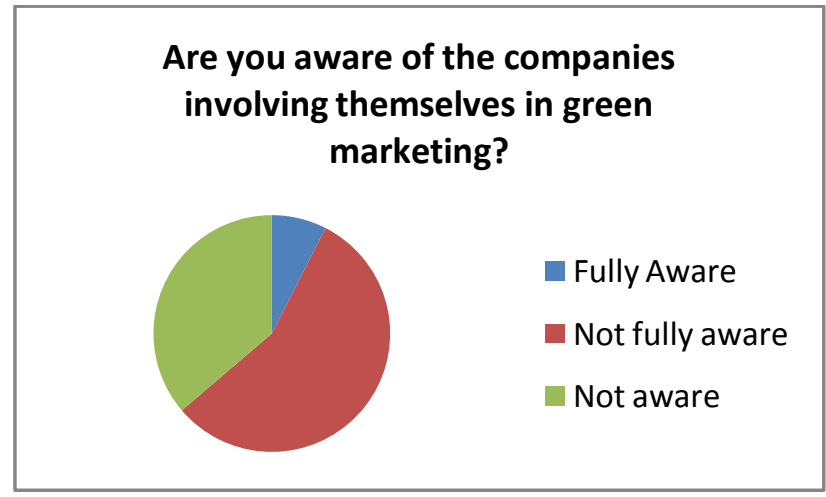

The above pie-chart depicts that more than half of the population surveyed is not fully aware about the companies involving themselves in green marketing. Everyone uses ' $n$ ' number of products since morning till night but people are highly unaware of the products being environment friendly or not.

6. Are you aware of the benefits of green products?

\begin{tabular}{|l|l|l|}
\hline Response & Number of Respondents & Percentage \\
\hline Not Fully Aware & 49 & 61.25 \\
\hline Fully aware & 19 & 23.75 \\
\hline Not aware & 12 & 15 \\
\hline Total & $\mathbf{8 0}$ & $\mathbf{1 0 0}$ \\
\hline
\end{tabular}

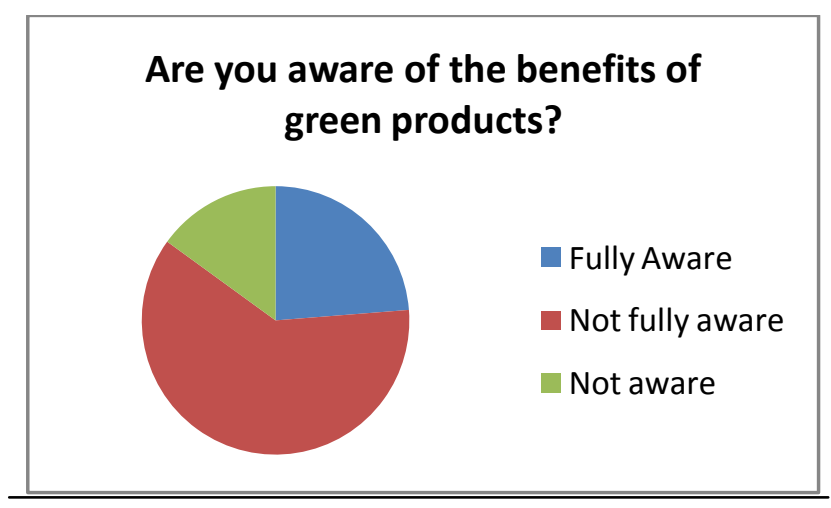


As depicted by the table, there is very high degree of unawareness among the students about the benefits of green products and ecological marketing. Most of them have a perception that green product just involves only recycling the old goods and using them, taking care of environment. But as we have seen green marketing is a very huge concept much beyond the above mentioned notions.

7. Does the green marketing campaign by the companies affect your purchase behaviour?

\begin{tabular}{|l|l|l|}
\hline Response & Number of respondents & Percentage \\
\hline Yes & 31 & 38.75 \\
\hline No & 8 & 10 \\
\hline Can't say & 5 & 6.25 \\
\hline May be & 37 & 46.25 \\
\hline Total & $\mathbf{8 0}$ & $\mathbf{1 0 0}$ \\
\hline
\end{tabular}

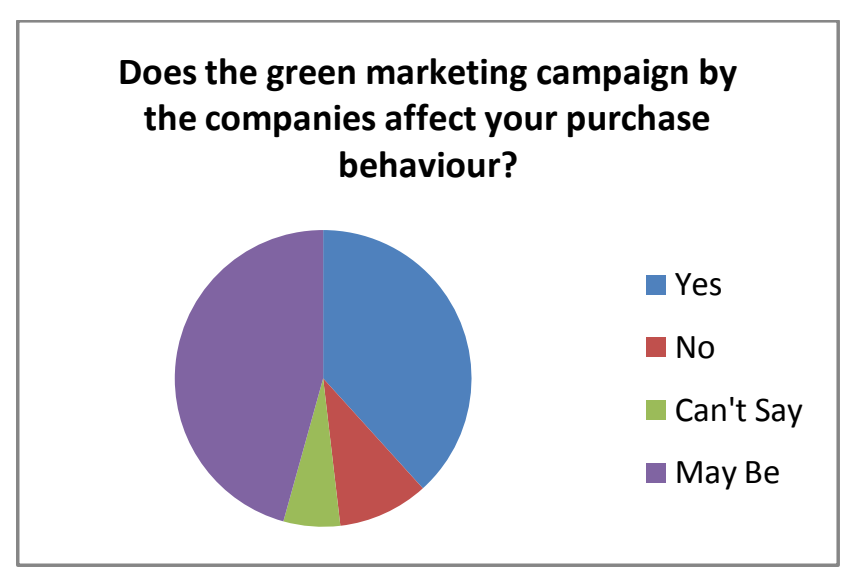

Around $38.75 \%$ gets affected by the green marketing campaign by the companies. Around $50 \%$ of the population is unaware about the impact generated on their purchase behavior by the campaign of the companies

8. Do you agree that green products unnecessarily adds to cost?

\begin{tabular}{|l|l|l|}
\hline Response & Number of respondents & Percentage \\
\hline Yes & 8 & 10 \\
\hline No & 50 & 62.5 \\
\hline Can't say & 10 & 12.5 \\
\hline May be & 12 & 15 \\
\hline Total & $\mathbf{8 0}$ & $\mathbf{1 0 0}$ \\
\hline
\end{tabular}

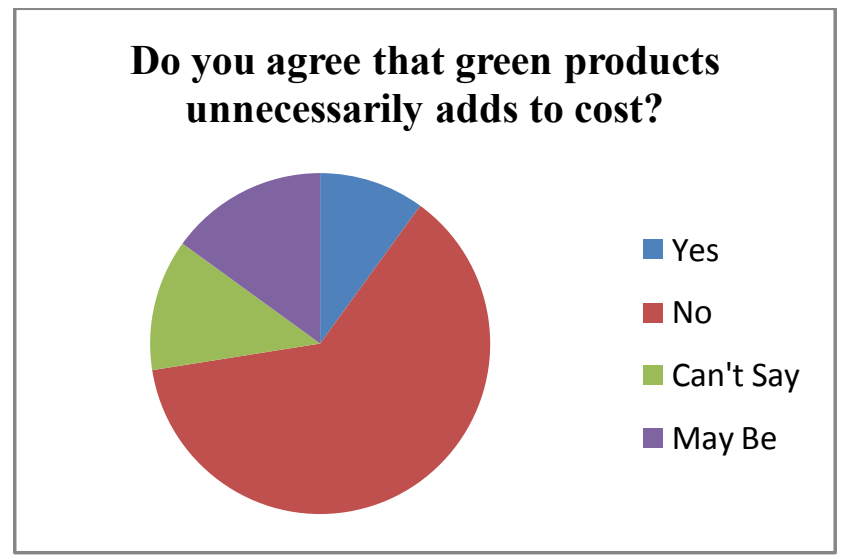

More than $60 \%$ people are unaffected by the myth that 'green products unnecessarily adds to cost'. This shows that most of the students act rationally and does not believe in myths. 


\section{Conclusion}

\section{High Degree Of Unawareness Among The Young Adult Students}

There is high degree of unawareness among the target population regarding the concept of green marketing, how it is going to affect the society and its benefits. This unawareness makes the Environmental campaign by the organization ineffective because till the time a person is unaware of the concept, idea and benefits of the green marketing, he or she will not be swayed by such campaigns. Because of this only, the purchase behavior of around $50 \%$ people surveyed does not get affected by the ecological marketing campaign of the firms.

\section{More Concern For Brand Than Prices And Eco-Friendliness}

Most of the students are concerned about the brand value of the product and not its price \& impact on the nature. But between prices and Eco-friendliness most of the people care for the nature and go for environment friendly products. This implies that if the big brands undertake green marketing on a large scale than they can create massive awareness among the students group and can encash on this. They give preference

to the factors as follows:

$$
\text { Brand }>\text { Price }>\text { Easy availability/Eco-friendliness. }
$$

\section{Almost All The States Have Similar Pattern}

The data collected pertain to students from 14 states. This means that almost all the students in the same age group of young adult( 17-25) display similar pattern irrespective of the geographical location and culture.

\section{References:}

[1]. Philip Kotler, Gary Armstrong, Prafulla Y. Agnihotri, Ehsan ul Haque, $13^{\text {th }}$ edition, "Principles of Marketing”, pp. 490-491.

[2]. Jacquelyn Ottman, "Green Marketing: opportunity for Innovation".

[3]. Census of India 2011, http://censusindia.gov.in/

[4]. Higher Education in India at a glance(2012), University Grants Commission,

[5]. http://www.ugc.ac.in/page/Reports.aspx

[6]. Jacquelyn Ottman's Article on the portal. http://www.sustainablebrands.com/news and views/articles/seven-myths-greenmarketing-stand-between-you-and-today $\% \mathrm{E} 2 \% 80 \% 99$ s-hottest-business-o

[7]. Sai Om Journal of Commerce and Management, (September 2012), Issue No.9 , Abhinav Journals. http://www.abhinavjournal.com/images/Commerce \%26 Management/Sep12/9.pdf 